\title{
Analysis on Predominant Periods Distribution by Microtremor Observations for Seismic Disaster Prevention in Yokohama, Japan Using GIS
}

\author{
Tsutomu Ochiai, Takahisa Enomoto \\ Kanagawa University, Kanagawa, Japan \\ Email: ochiai@kanagawa-u.ac.jp
}

How to cite this paper: Ochiai, T. and Enomoto, T. (2019) Analysis on Predominant Periods Distribution by Microtremor Observations for Seismic Disaster Prevention in Yokohama, Japan Using GIS. Journal of Geographic Information System, 11, 579-594.

https://doi.org/10.4236/jgis.2019.115036

Received: September 10, 2019

Accepted: October 19, 2019

Published: October 22, 2019

Copyright $\odot 2019$ by author(s) and Scientific Research Publishing Inc. This work is licensed under the Creative Commons Attribution International License (CC BY 4.0).

http://creativecommons.org/licenses/by/4.0/

\begin{abstract}
In recent years, predictions of damage from earthquakes have been made on a prefectural scale, and expectations exist that more detailed damage forecasts should be made even on a city/town/village scale. It is important to know detailed ground characteristics to do damage prediction on a fine scale. Using GIS is the best way to communicate this planar disaster prevention information to the general public. Yokohama City is the second largest city in Japan and developed as part of the capital region of Metropolitan Tokyo. Recently, the population of this city has reached about 3,000,000, and economic and cultural facilities, social infrastructure, and residential complexes are concentrated in this city. The capital region, including Yokohama City, was attacked by the 1923 Great Kanto Earthquake (M7.9) and Yokohama City was devastated by this earthquake. From the research so far, it is known that the H/V spectrum obtained from microtremor observation has a good correlation with the ground characteristics. The authors have been conducting high-density tremor observations that have been ongoing since the 1990s, mainly in Kanagawa Prefecture, Japan. Here, we have organized the predominant periods obtained from the observation results for Yokohama City. The entirety of Yokohama City was divided into $250 \mathrm{~m} \times 250 \mathrm{~m}$ meshes and their centers were used as microtremor observation sites. Excluding sites that could not be used due to geographical conditions, observations were made at approximately 5700 sites. So, we compared the data obtained separately, such as the period, terrain classification, and amplification characteristics. The distribution maps of predominant periods in Yokohama City show that the city contains a lot of artificially transformed land, and consequently, the distribution of predominant periods is not uniform. However, it can be seen that the periods become
\end{abstract}


gradually longer, moving from the higher elevation eastern part toward the lower elevation western part. Investigation of the site amplification factors and detailed topographical classifications indicates a clear correlation with the predominant period distribution.

\section{Keywords}

Microtoremor, Distribution of Predominant Periods, H/V Spectral Ratio, Ground Motion Characteristics, Yokohama City of Japan

\section{Introduction}

In recent years, predictions of damage from earthquakes have been made on a prefectural scale, and expectations exist that more detailed damage forecasts should be made even on a city/town/village scale. Behind such investigation activities are the fact that earthquake motions are greatly affected by the epicenter characteristics, propagation characteristics, and ground characteristics, and consequently regional differences in damage occur, even with earthquakes of the same magnitude, due to differences in these characteristics. When considering disaster prevention measures, it is essential to compare and evaluate the relationships among propagation characteristics, ground characteristics, and subsurface structures. In order to clearly identify surface-layer ground motion characteristics in particular, various methods have been used for investigation, and microtremor observation is one of these methods.

It's very important to know soil conditions in order to predict seismic damage for human losses due to structural damage generated by ground shaking intensity in cases of earthquake event. In Japan, many local governments develop seismic damage predictions due to the possible seismic faults related to the areas covered by its governmental responsibility. In this case, the soil conditions are estimated by geotechnical data such as borehole data and geological maps, as well as the geographical maps scaled at 1:50,000 published by the Geospatial Information Authority of Japan. These data are very effective and useful for seismic disaster prevention in relatively wide areas on the scale of a city. These however use the static soil characteristics and do not take dynamic characteristics such as predominant period and amplification of soil into consideration in the seismic damage evaluation process.

We think that it's also very important to know the dynamic characteristics of the soil condition, and so we would like to develop the high density microtremor observation and to know the predominant period and amplification of soil conditions. Figure 1 shows the schema of this research.

From past observations and applying a theoretical approach, it is presumed that surface wave components are dominant in microtremors, and that, especially in a ground structure in which relatively soft sedimentary layers are present, an H/V spectral ratio based on the features of the Rayleigh wave can be 


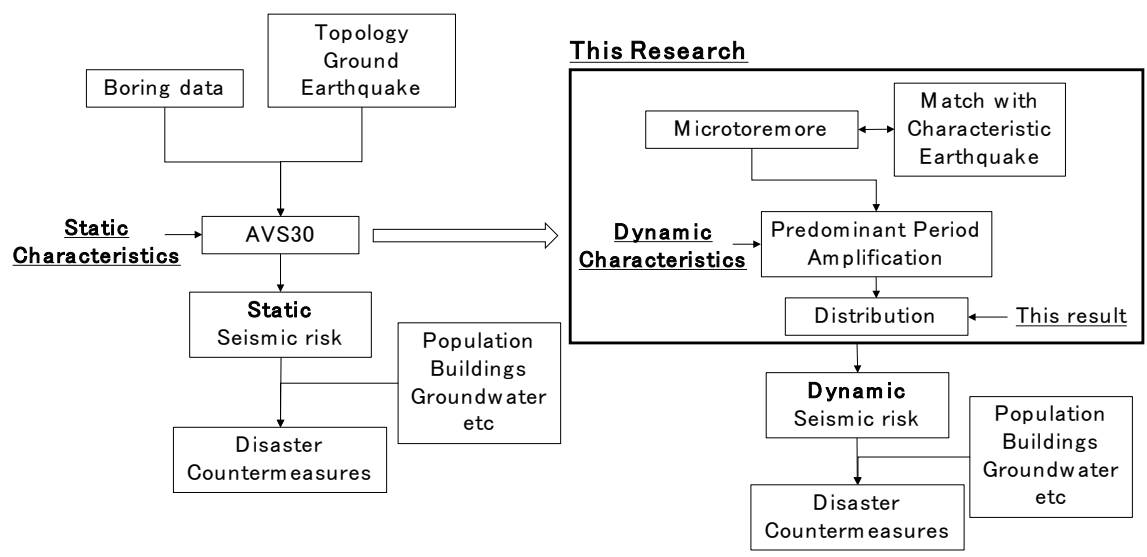

Figure 1. Schema of this research.

considered usable in estimating the predominant periods unique to the target ground.

As for the method of ascertaining ground motion characteristics, soil boring, which can provide accurate data on the subsurface structure of the target area, is ideal, but is time-consuming and expensive. Therefore, microtremor observation, a simple method of identifying ground motion characteristics, has gained a great deal of attention and many studies have been carried out using this method (Example, Nakamura [1], Ohmachi et al. [2], Maruyama et al. [3], Motoki et al. [4]).

Among the 50 major cities of the world, the Tokyo and Yokohama region, which includes many industrial zones, has a much higher risk index than cities in other countries according to "A Risk Index for Megacities," and is projected to suffer major damage if struck by earthquakes in particular [5].

In Europe, many hazard maps use ground characteristics like Navarro et al. [6], Benito et al. [7], Gaspar-Escribano et al. [8], Rota et al. [9]. The same is true in the United States (Pertersen et al. [10]).

In Japan, terrain classification data and ground amplification data are maintained for the whole of Japan (Wakamatsu et al. [11], Fjimoto et al. [12]. However, these are arranged in $250 \mathrm{~m}$ grids. The authors developed terrain classification and ground amplification on a 50m grid for Kanagawa Prefecture (Ochiai et al. [13]).

In this study, we aimed to organize the predominant period distribution obtained from the high density microtremor observations that have been conducted so far in Yokohama City, and to use the information of surface layer ground motion characteristics using GIS. In addition, we compared the predominant period distribution with the $50 \mathrm{~m}$ grid terrain classification and ground amplification.

\section{Topography and Geology of Yokohama City}

Figure 2 shows the Landform Classification of Yokohama City. This figure is a map developed by MLIT (Ministry of Land, Infrastructure, Transport and Tourism) 


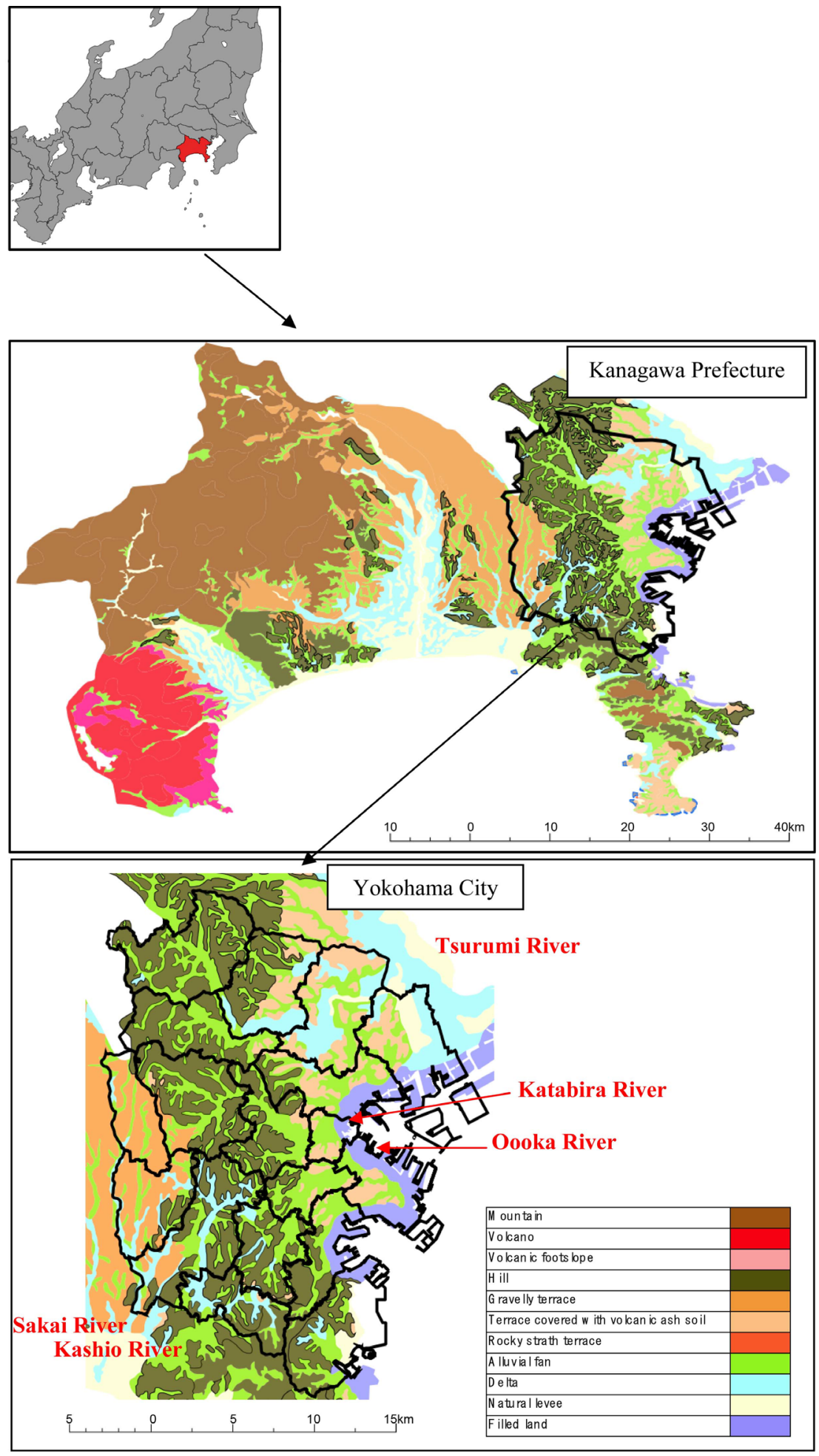

Figure 2. Landform classification map of Yokohama City. (1/200,000 Landform Classification (Kanagawa) [14].)

and available as GIS data [14]. The topography of Yokohama City can be classified into hilly areas, plateaus, terraces, lowlands, and landfills. The hilly areas and plateaus account for approximately $70 \%$ of the whole city, with the remain- 
ing 30\% consisting of alluvial plains along rivers and landfills in coastal areas [15].

Hilly areas are distributed somewhat to the west of the central area of the city, cutting through the city in the north-south direction. The north and south sides of these hilly areas exhibit different characteristics, separated as they are by the Katabira River, which runs through Hodogaya Ward, Asahi Ward, etc. The hilly area on the north side is located at the southern tip of the Tama Hills, and its elevation increases from $60 \mathrm{~m}$ to $100 \mathrm{~m}$ toward the north. The hilly area on the south side occupies the northern tip of the Miura Hills, which is adjacent to the Miura Peninsula, and its elevation increases from $80 \mathrm{~m}$ to $160 \mathrm{~m}$ toward the south.

The plateaus and terraces are located on both the east and west sides of the hilly areas. The plateau on the east side is called the Shimosueyoshi Plateau, named after an area in the Tsurumi Ward, and continues to an area near the Tsurumi River, with an elevation of between $40 \mathrm{~m}$ and $60 \mathrm{~m}$. The plateau on the west side is located at the eastern tip of the Sagamihara Plateau and its elevation decreases from $70 \mathrm{~m}$ to $30 \mathrm{~m}$ toward the south. Additionally, the plateaus and terraces have been extensively eroded and, in terms of topography, the plateau spreads like tree branches and is full of undulations. Extensive deepening and lateral erosion have occurred in the Tsurumi, Katabira, Oooka, Kashio, and Sakai Rivers, and their tributaries, cutting into the Kazusa Group of marine strata and creating alluvial formations with thick layers. In terms of geological distribution, the Kazusa Group forms the base of Yokohama City while the Sagami Group of marine strata inconsistently covers this base, forming the hilly areas and plateaus.

The lowlands include valley plains formed by rivers cutting into the hilly areas and plateaus, as well as coastal lowlands. There are also landfills on the coastal area, resulting in mostly artificial shorelines. As for islands, there is Nojima Island in Kanazawa Ward (Hakkeijima Island is an artificial island), making the Nojima Coast the only natural beach in Yokohama.

\section{Observation Sites}

The authors have been continuously carrying out high-density tremor observations since the 1990s, mainly in Kanagawa Prefecture (Example Ochiai et al. [16] and Ueno et al. [17]). The entirety of Yokohama City was divided into $250 \mathrm{~m} \times$ $250 \mathrm{~m}$ meshes and their centers were used as microtremor observation sites. Excluding sites that could not be used due to geographical conditions, observations were made at approximately 5700 sites. A servo velocity meter was used, and three components-two horizontal components (NS and EW) and a single up-down component (UD)-were observed. The mesh code conforms to JIS (JIS $\mathrm{X}$ 0410). Table 1 shows a list of observation points for each ward.

\section{Microtremor Observation Method and Analysis Method}

For microtremor observations, a servo velocity meter was used to obtain 18,000 
Table 1. Number of observation sites in each ward.

\begin{tabular}{cccccccccc}
\hline & Kohoku & Aoba & Midori & Kanagawa & Naka & Isogo & Minami & Konan & Asahi \\
\hline Count & 411 & 455 & 365 & 375 & 221 & 263 & 201 & 281 & 403 \\
& Seya & Totsuka & Kanazawa & Izumi & Tsurumi & Hodogaya & Tsuzuki & Nishi & Sakae \\
Count & 210 & 482 & 421 & 306 & 347 & 294 & 362 & 99 & 207 \\
& & & & & & & & Total & 5703 \\
\hline
\end{tabular}

pieces of velocity data (a total of three components, i.e., two horizontal components and a single up-down component) with a sampling frequency of $100 \mathrm{~Hz}$ and an observation time of 180 seconds.

Channels 1, 2, and 3 of the microtremor sensor were used for the NS component (horizontal, north-south direction), the EW component (horizontal, east-west direction), and the UD component (up-down direction), respectively. The orientations of channels 1 and 2 were aligned using a compass, and channel 3 was placed horizontally based on a level provided in the microtremor sensor body. The observation site was selected avoiding places where traffic vibration was intense.

Subsequently, a microtremor meter, an amplifier, and an A/D port were connected to each microtremor sensor, and then a PC was activated to begin observations using a microtremor observation program. Simultaneously, the GPS-based positional information of the observation site (latitude and longitude) and the conditions of the surrounding area were recorded in a field notebook.

For the analysis, the window size was set to $20.48 \mathrm{sec}$, and window selection was made using an amplitude level based on ex situ processing. The Fourier spectrum was calculated by FFT for each divided data. The spectrum data was smoothed with the Parzen Window. The calculated H/V spectral ratio was obtained by dividing the mean square of NS and EW by UD. The H/V spectral ratio was obtained for each divided data and the average was used. The predominant period was calculated for the maximum value of the averaged $\mathrm{H} / \mathrm{V}$ spectrum ratio. These use a series of programs.

For the most part, a predominant period in the vicinity of 0.1 to 1.5 seconds was selected. In the analysis, an automated analysis program was created to compute the H/V spectral ratio, and then the predominant periods were extracted from the output results shown in Figure 3. The locations where it was difficult to extract the predominant period due to the shape of the H/V spectral ratio were determined based on the surrounding results.

\section{Prominent Period Distribution}

As shown in Table 1, Yokohama City is divided into 18 wards in total. The topography and geology are spread from the northwestern part to the eastern part as shown in Figure 2 and plateaus and hilly areas extend and continue to the lowlands in the eastern part. In addition, within the plateau and hilly area, rivers that open and flow are developed. 
Averaged Microtremors Data Sheet

Station Name: X58Y13

Add.: N/A

$\begin{array}{lccc}\text { Long.: } & 139.450928 & \text { Lat.: } & 35.394432 \\ \text { X: } & 0.00 & \text { Y: } & 0.00\end{array}$

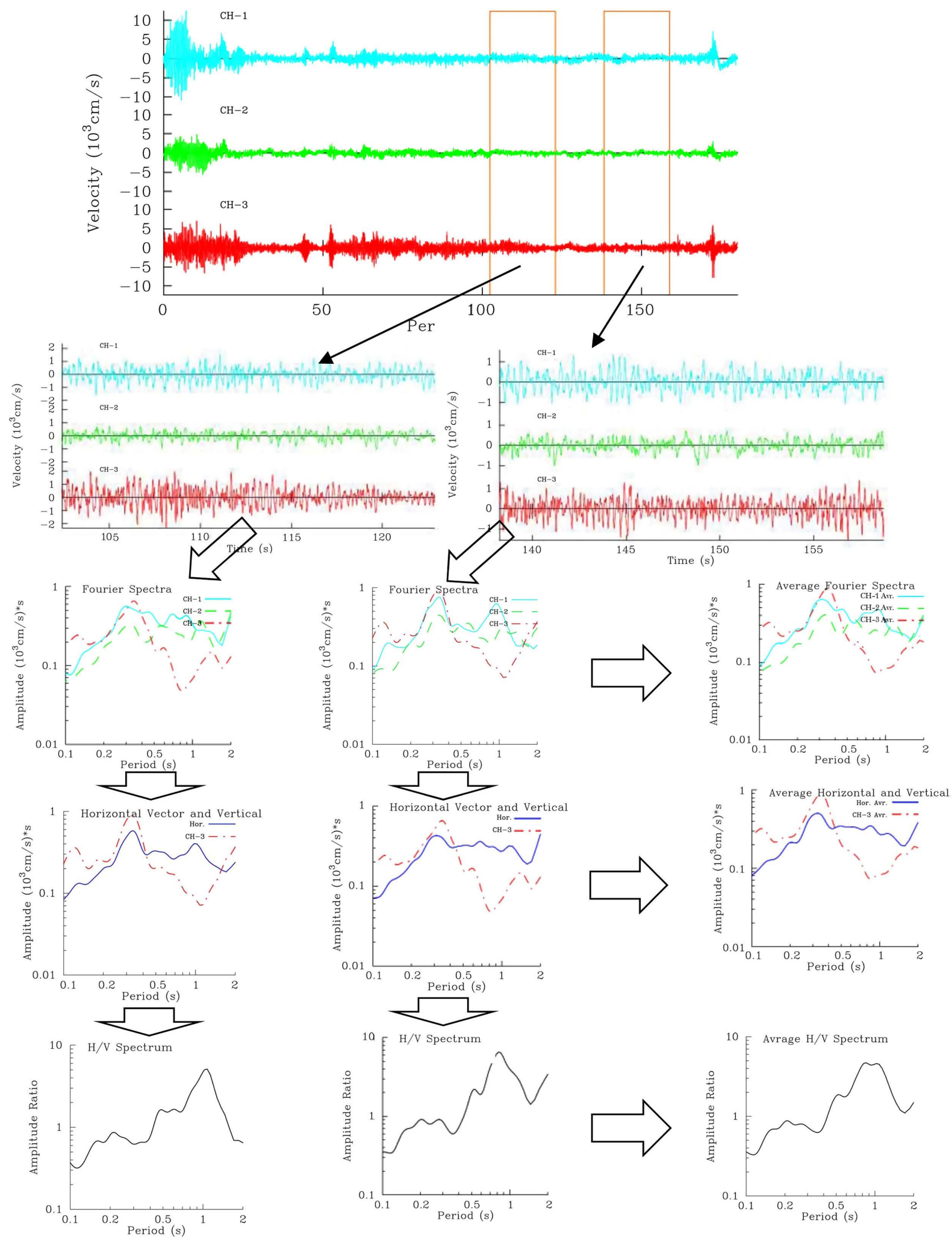

Figure 3. Methods of analyzing microtremor observation results. 
Here, the predominant period distribution extracted from the H/V spectral ratio of the microtremors is organized by area using GIS and shown in the figure. The method of extracting the predominant period is as described in Chapter 4. Figure 4 illustrates the 5 wards in the north of Yokohama City (Aoba, Tsuzuki, Midori, Kohoku, and Tsurumi). Figure 5 shows 7 wards in central Yokohama (Seya, Asahi, Hodogaya, Kanagawa, Minami, Naka and Nishi). Figure 6 shows 6 wards in southern Yokohama (Konan, Minami, Isogo, Totsuka, Kanazawa and Sakae). From the distribution maps by ward in each area, the predominant period distribution that seems to be attributed to the topography, geology and the characteristics of the ground is recognized.

Figure 4 is explained for each ward. In Aoba Ward, the predominant period is shorter than about $0.5 \mathrm{~s}$. Among them, it can be confirmed that the predominant period is slightly longer in the southwestern part. Midori Ward shows the same tendency as Aoba Ward. However, at the eastern end, the predominant period is as long as $0.8 \mathrm{~s}$. Tsuzuki Ward also has a short predominant period as a whole, but there are some points where the predominant period is longer than $1.0 \mathrm{~s}$. In Kohoku Ward, the predominant period is a little longer from $0.5 \mathrm{~s}$ to $1.0 \mathrm{~s}$ near the center of ward. This is consistent with soft ground at low elevation. Details of comparison with elevation etc. are given in Chapter 6. Tsurumi Ward has a short predominant period only in the central part. The center of Tsurumi Ward is a plateau with high elevation.

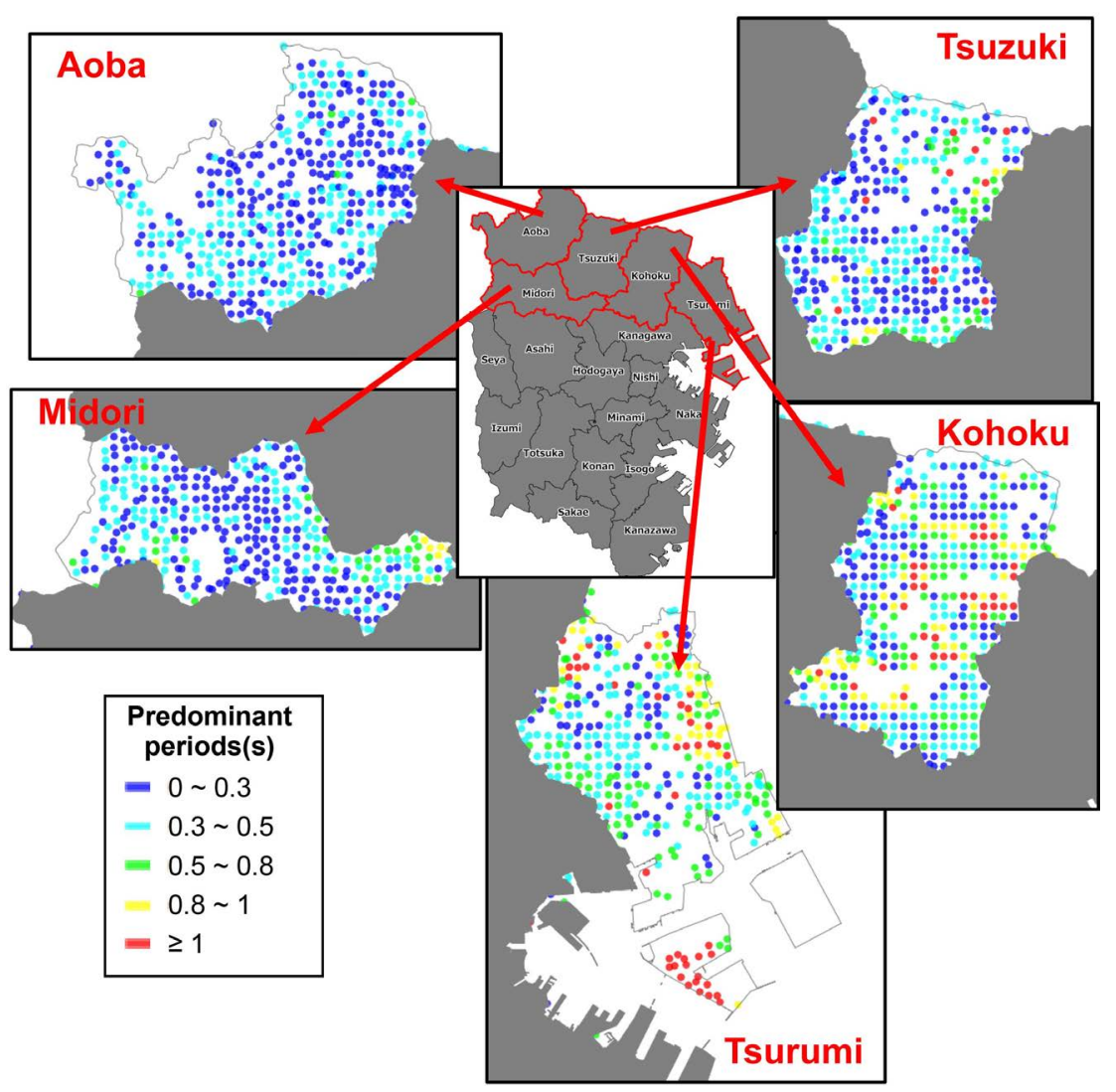

Figure 4. Distribution of predominant periods in the northern part of Yokohama City. 


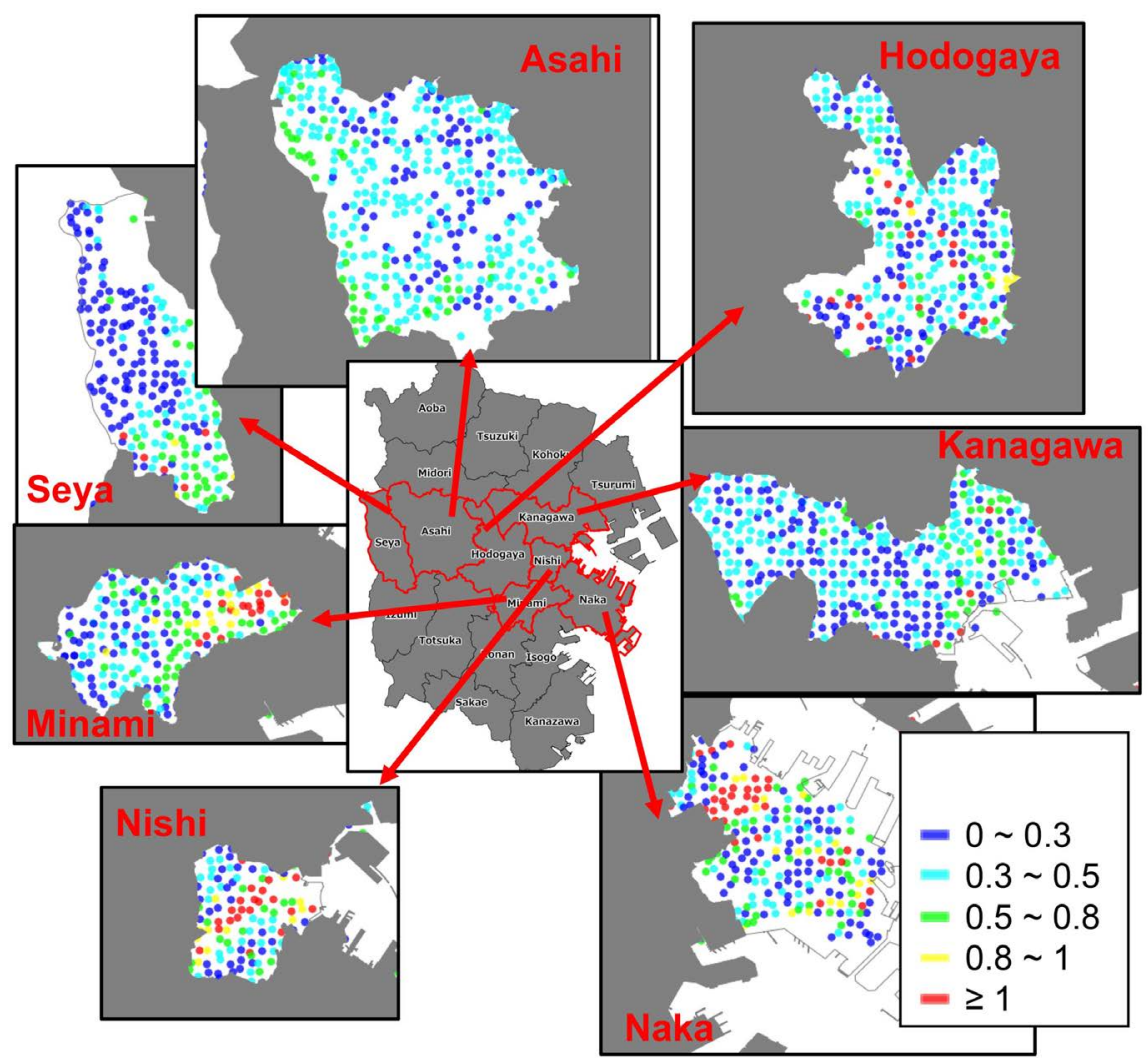

Figure 5. Distribution of predominant periods in the central part of Yokohama City.

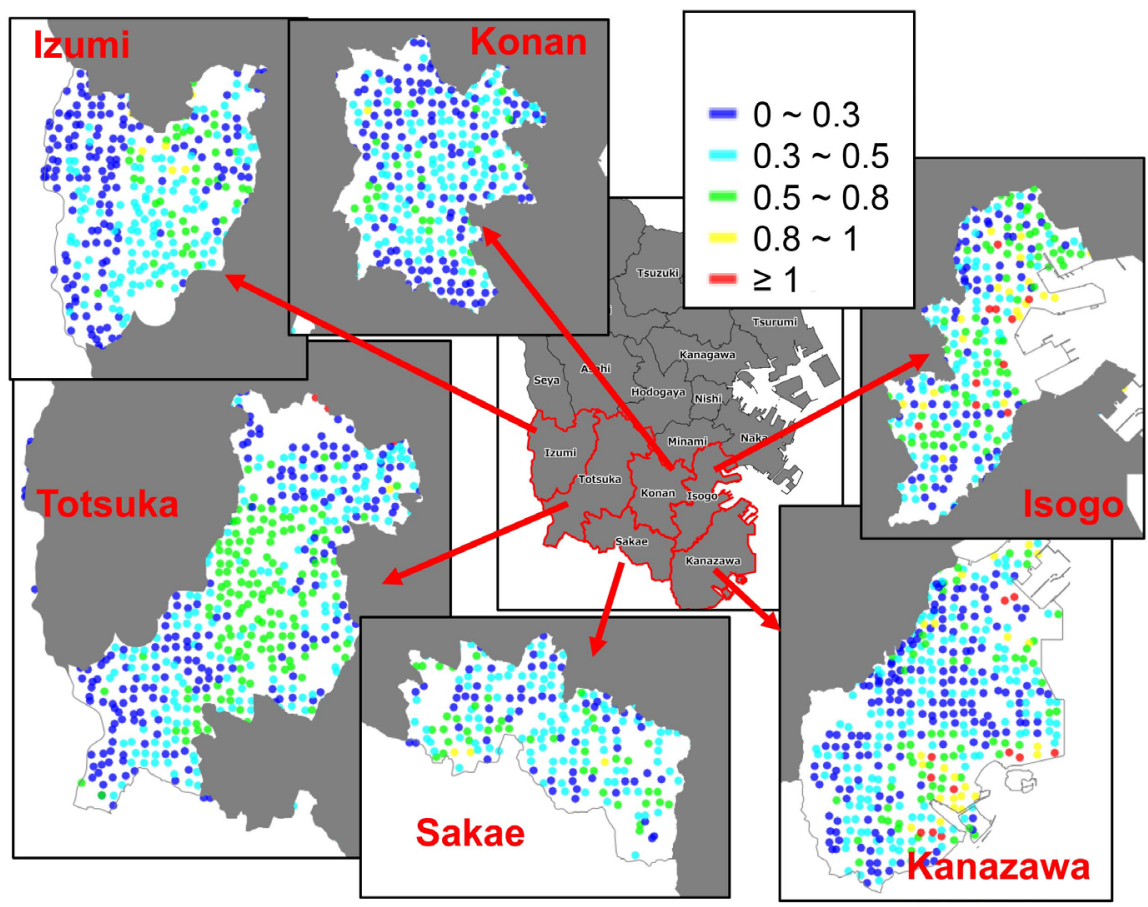

Figure 6. Distribution of predominant periods in the southern part of Yokohama City.

Figure 5 is explained for each ward. Seya Ward has a slightly longer predominant period in the southeast. This is an area where the elevation is slightly 
lower. Asahi Ward also has a slightly longer predominant period in the south. This is different from other areas. In Hodogaya Ward, areas with a predominant period of $1.0 \mathrm{~s}$ or more are distributed on aline. This is the soft ground along the river. Kanagawa Ward has a rather long predominant period on the eastern coast. In the Nishi Ward and Naka Ward, zones of long and short areas are distributed on aline, similar to the river region of Hodogaya Ward. Minami Ward has a long period at the low elevations in the southeast.

Figure 6 is explained for each ward. Izumi Ward and Totsuka Ward have a rather long period of $0.5 \mathrm{~s}$ to $0.8 \mathrm{~s}$ in the central part of the ward. This is an area with a high elevation. Like Asahi Ward in Figure 5, the trend is slightly different from other areas. In Konan Ward, the change is small, but areas with a short predominant period are distributed on aline. Isogo Ward and Kanazawa Ward have a long period along the coast. Sakae Ward has a predominant period of about $0.3 \mathrm{~s}$ as a whole.

\section{Investigation of Ground Motion Characteristics}

\subsection{Investigation of Periods and Elevation, Topography}

The distribution of the predominant periods of Yokohama City, the elevation distribution by $5 \mathrm{~m} \mathrm{DEM}$, and the land classification map according to the land classification survey are shown in Figure 7 respectively. The $5 \mathrm{~m}$ DEM and land classification map are data published by the Geospatial Information Authority of Japan and the Ministry of Land, Infrastructure, Transport and Tourism [15]. The land classification map of Figure 7 is more detailed than that of Figure 2.

From the elevation distribution, it is understood that the elevation of Yokohama City tends to gradually increase from east to west.

In the areas along the rivers where the predominant periods were expected to become longer because of the accumulated soft layers, they were instead found to be shorter moving toward the mountainous area on the western side of Yokohama City because this area has higher elevation and hosts the upstream portion of the rivers, as well as to be longer moving downstream. This is presumed to be because soft layers did not accumulate upstream but flowed downstream.

Sites with long predominant periods were also found in the landfill areas along the coast in the eastern part of the city where soft ground layers accumulated and were covered with fill soil to increase the total layer thickness.

In the Asahi and Izumi Wards in the interior area, the opposite phenomenon from the coastal area was observed. That is, as the elevation increased, the predominant periods became longer. This is presumed to be because the mountainous sides of the wards contain accumulated loam layers, whose accumulated thickness caused the periods to become longer.

The predominant period is often long at low elevation where soft ground is deposited. However, even if the elevation is high as in the case, for example, where the surface soil structure includes the loam layer, the predominant period may be long. The difference between the change of the predominant period in 


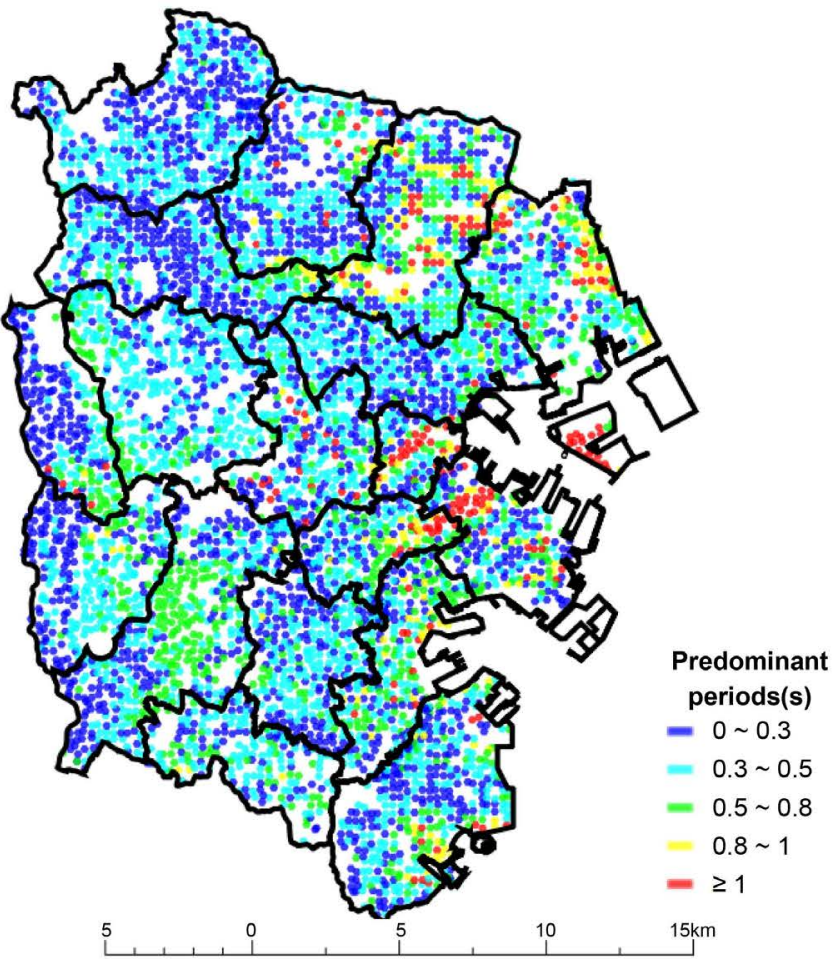

Distribution of predominant periods

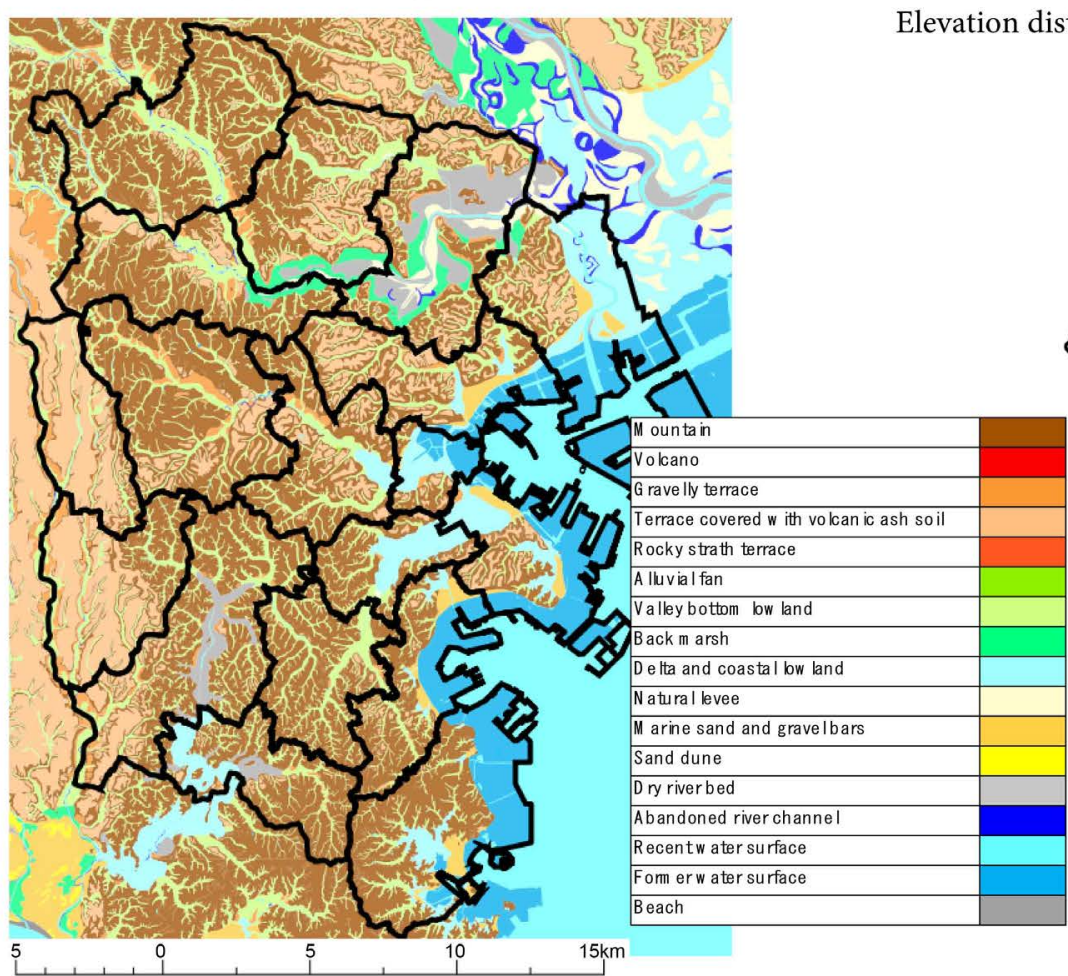

Land Classification Map

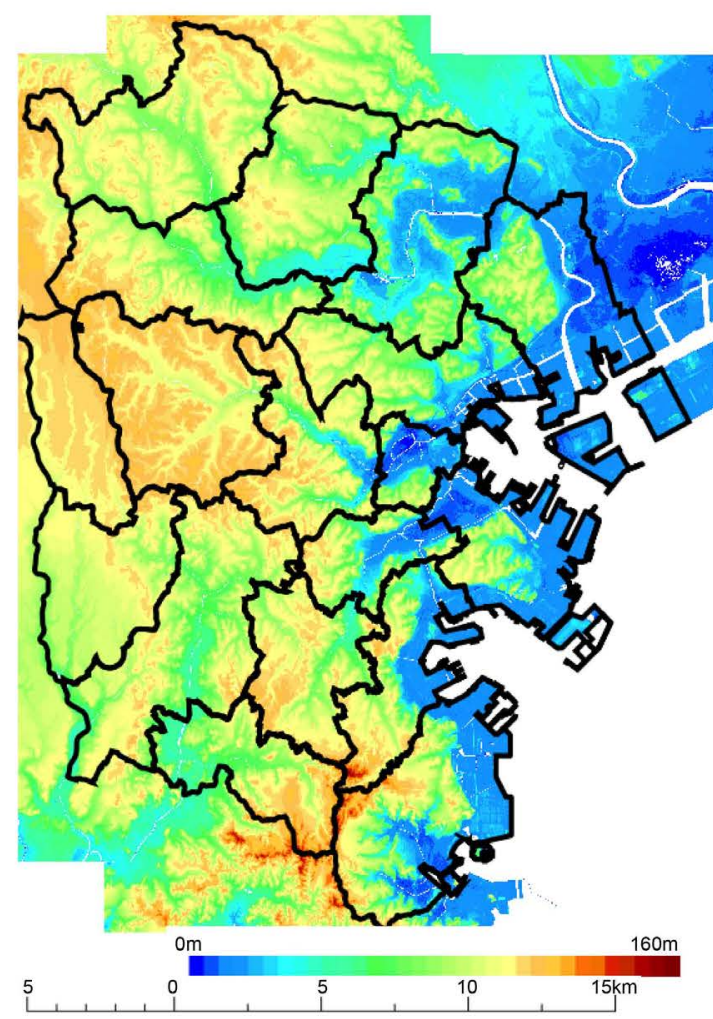

Elevation distribution by $5 \mathrm{~m}$ DEM

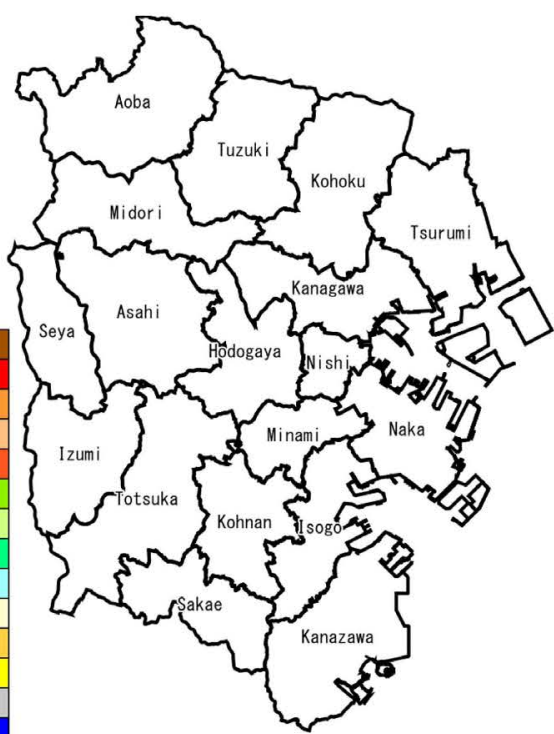

Ward NameMap

Figure 7. Distribution of predominant periods, Elevation distribution and Land Classification Map.

the soft ground and the change of the predominant period in the loam plateau is presumed to be due to the characteristics of the soil. This will be further investi- 
gated in the future.

In Figure 7, the valley bottom lowland can be confirmed in detail. However, the distribution of the predominant periods does not reflect the detailed valley bottom lowland. This microtremor observation is performed at intervals of 250 $\mathrm{m}$. It is possible that detailed valley bottom lowlands can be reflected by making observations at a finer resolution.

\subsection{Investigation of Distribution of Predominant Periods and Detailed Topographical Classification and Amplification Factors}

The authors have created detailed topographical segmentation maps and ground amplification factor maps using GIS from the viewpoint of earthquake disaster prevention in Kanagawa Prefecture [13]. These maps are created by digitizing the existing paper-based topographic maps and surface geological maps and interpreting them on a $50 \mathrm{~m} \times 50 \mathrm{~m}$ mesh basis. These maps also reflect detailed surface ground characteristics.

As Figure 8 shows, Yokohama City has many artificially-remodeled lands, so the distribution of predominant periods was not uniform. This is presumed to be due to the fact that the interior region of Yokohama City is hilly and has undulating topography, as well as the fact that the top layer is covered by loam and a lot of artificially transformed land is located throughout the city. The following can be presumed regarding artificially transformed land: The strata of cut earth made by scraping of hills are stable, and therefore have short predominant periods.
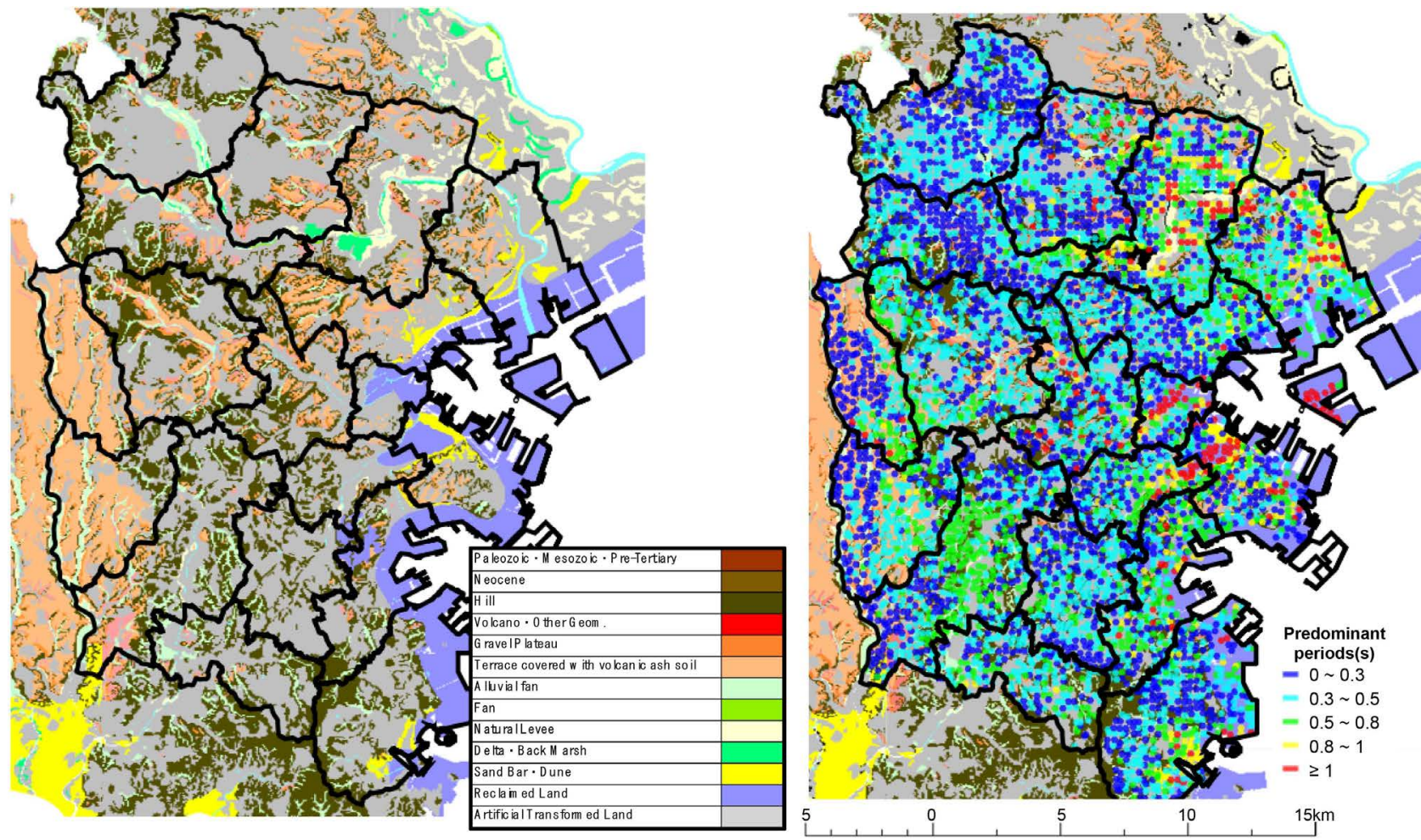

Figure 8. Detailed topographical segmentation map and distribution of predominant periods in the Yokohama City. 
In contrast, embankments consisting of new strata are unstable and soft, and therefore have long predominant periods. At present, the detailed data of such alteration sites is being organized. In the future, we think that further examination can be performed by comparing with those data.

Wide variations in predominant periods were observed among landfills and reclaimed land. It is presumed that since the landfills and reclaimed land on the western side of the old coastline were created by filling in areas that used to be hilly, the depth of the soft ground layer is shallow, making the predominant periods short. In contrast, the landfills and reclaimed land on the eastern side of the old coastline were created by filling in areas of the sea along the coast, leaving a deep soft ground layer made up of sludge, etc., which results in long predominant periods. However, it is speculated that the ground characteristics of landfill sites vary greatly depending on the soil used for landfill and the landfill method.

Figure 9 is map of amplification factors. The amplification factor was set using the empirical formula of AVS30 and the amplification factor of peak velocity, by obtaining AVS30 from the created topographical map. The amplification factor was set by Midorikawa et al. [18]. And AVS30 was set by Matsuoka et al. [19]. Amplification characteristics increase as the ground becomes softer. Consequently, where the ground is soft, earthquake damage might be more severe, such as causing buildings to collapse, and shaking is sometimes more violent,
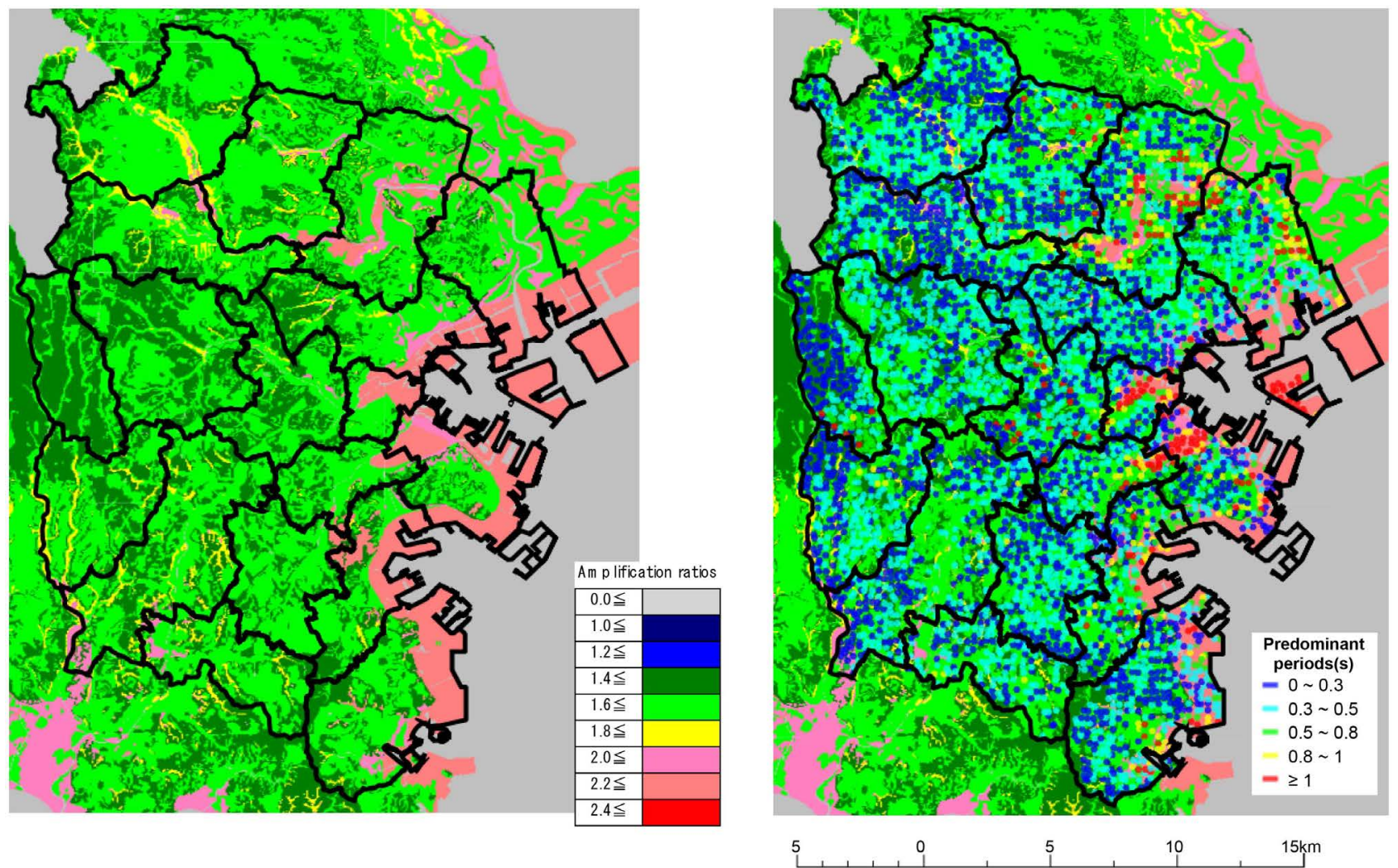

Figure 9. Ground amplification factor maps and distribution of predominant periods in the Yokohama City. 
even if the site is far away from the epicenter. In Yokohama City, the site amplification factor is 2.0 or greater in the reclaimed lands, and the number gets smaller moving toward the interior, indicating clear correlation with the predominant period distribution according to Figure 9.

\section{Summary}

We used a GIS in an effort to organize and display the distribution of predominant periods obtained from high-density microtremor observations in Yokohama City, with the goal of utilizing the information in evaluating microtremor characteristics.

The distribution maps of predominant periods in Yokohama City show that the city contains a lot of artificially transformed land, and consequently the distribution of predominant periods is not uniform. However, it can be seen that the periods become gradually longer moving from the eastern part with higher elevation toward the western part with lower elevation. This is presumed to be due to the fact that the interior region of Yokohama City is hilly and has undulating topography, as well as the fact that the top layer is covered by loam and a lot of artificially transformed land is located throughout the city. The following can be presumed regarding artificially-transformed land: The strata of cut earth made by scraping hills are stable, and therefore have short predominant periods. In contrast, embankments consisting of new strata are unstable and soft, and therefore have long predominant periods.

Investigation of the site amplification factors and detailed topographical classifications indicates a clear correlation with the predominant period distribution.

The author is also examining not only the predominant period, but also the value of the H/V spectrum ratio. In the future, we would like to promote further research so that they can be used to obtain useful data for earthquake disaster prevention.

And in the future, I would like to use the distribution of the predominant periods obtained here as a base map and combine it with other information (population, buildings, groundwater, etc.) to improve disaster prevention capabilities.

\section{Conflicts of Interest}

The authors declare no conflicts of interest regarding the publication of this paper.

\section{References}

[1] Nakamura, Y. (1989) A Method for Dynamic Characteristics Estimation of Subsurface Using Microtremor on the Ground Surface. Quarterly Report of RTRI, 30 , 25-33.

[2] Ohmachi, T., Konno, K., Endoh, T. and Toshinawa, T. (1994) Refinement and Application of an Estimation Procedure for Site Natural Periods Using Microtremor. Journal of JSCE, 489, 251-261. https://doi.org/10.2208/jscej.1994.489 251 
[3] Maruyama, Y., Yamazaki, F., Motomura, H. and Hamada, T. (2001) Estimation of Strong Motion Distribution Using the H/V Spectrum Ratio of Microtremor. Journal of JSCE, 675, 261-272. https://doi.org/10.2208/jscej.2001.675 261

[4] Motoki, K., Watanabe, T., Kato, K., Takesue, K., Yamanaka, H., Iiba, M. and Koyama, S. (2016) Characteristics of Temporal and Spatial Variation in Peak Periods of Horizontal to Vertical Spectral Ratios of Microtremors. Journal of Structural and Construction Engineering, 81, 437-445. https://doi.org/10.3130/aijs.81.437

[5] Voss, S. (2006) A Risk Index for Megacities. http://www.actuaries.jp/lib/meeting/reikai18-2-siryo.pdf

[6] Navarro, M., Garcia-Jerez, A., Alcala, F.J., Vidal, F. and Enomoto, T. (2014) Local Site Effect Microzonation of Lorca Towin (SE Spain). Bulletin of Earthquake Engineering, 12, 1933-1959. https://doi.org/10.1007/s10518-013-9491-y

[7] Benito, B., Navarro, M., Vidal, F., Gaspar-Escribano, J., Garcia-Rodriguez, M. and Solares, J.M.M. (2010) A New Seismic Hazard Assessment in the Region of Andalusia (Southern Spain). Bulletin of Earthquake Engineering, 8, 739-766.

https://doi.org/10.1007/s10518-010-9175-9

[8] Gaspar-Escribano, J., Navarro, M., Benito, B., Garcia-Jerez A. and Vidal, F. (2010) From Regional to Local-Scale Seismic Hazard Assessment: Examples from Southern Spain. Bulletin of Earthquake Engineering, 8, 1547-1567. https://doi.org/10.1007/s10518-010-9191-9

[9] Rota, M., Penna, A., Strobbia, C. and Magenes, G. (2011) Typological Seismic Risk Maps for Italy. Earthquake Spectra, 27, 907-926. https://doi.org/10.1193/1.3609850

[10] Petersen, M.D., et al. (2015) The 2014 United States National Seismic Hazard Model. Earthquake Spectra, 31, S1-S30. https://doi.org/10.1193/120814EQS210M

[11] Wakamatsu, K., Matsuoka, M., Kubo, S., Hasegawa, K. and Sugiura, M. (2004) Development of GIS-Based Japan Engineering Geomorphologic Classification Map. Journal of JSCE, 759, 213-232. https://doi.org/10.2208/jscej.2004.759 213

[12] Fujimoto, K. and Midorikawa, S. (2006) Relationship between Average Shear-Wave Velocity and Site Amplification Inferred from Strong Motion Records at Nearby Station Pairs. The Journal of JAEE, 6, 11-22. https://doi.org/10.5610/jaee.6.11

[13] Ochiai, T. and Enomoto, T. (2019) Development of Detailed Micro-Land Form Database and Its Application to Site Amplification Characteristics in Kanagawa Prefecture, Japan. JGIS, 11, 66-81. https://doi.org/10.4236/jgis.2019.111006

[14] MLIT, Land Survey (Land Classification Basic Survey, Water Basic Survey etc.). http://nrb-www.mlit.go.jp/kokjo/inspect/inspect.html

[15] Yokohama City Institute of Environmental Science (2003) Yokohama City Ground Environment Investigation Report.

[16] Ochiai, T., Yamamoto, T., Hattori, H. and Enomoto, T. (2003) Study on Zoning for Ground Shaking Characteristics of Surface Soil Structure in Sagami Plain Using Spatially Dense Microtremor Measurements. Journal of ISSS, 5, 21-26.

[17] Ueno, N., Enomoto, T. and Yamamoto, T. (2010) Investigation of Illustration and Its Characteristics for Spatial Distribution of Predominant Periods Obtained from High Density Microtremor Observations in Yokohama City by Using GIS. The 13 th Japan Earthquake Engineering Symposium, Tsukuba, 17-10 November 2010, GO31-FRI-PM-3.

[18] Midorikawa, S., Matsuoka, M. and Sakugawa, K. (1994) Site Effects on Strong-Motion Records Observed during the 1987 Chiba-Ken-Toho-Oki, Japan Earthquake. Pro- 
ceedings of 9 th Japan Earthquake Engineering Symposium, Vol. 3, 85-90.

[19] Matsuoka, M. and Midorikawa, S. (1994) The Digital National Land Information and Seismic Microzoning. The 22nd Symposium of Earthquake Ground Motion, Tokyo, 31 October 1994, 23-34. 